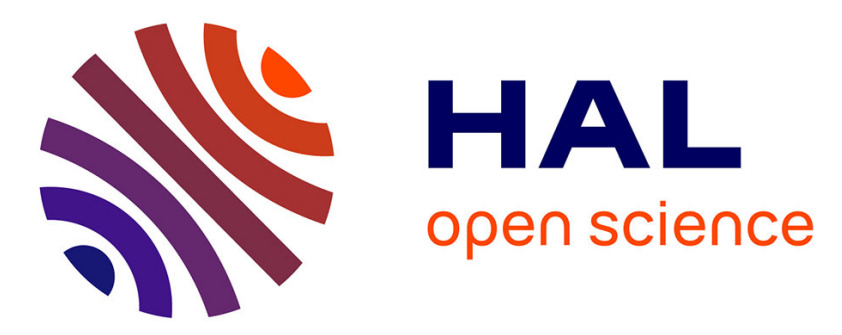

\title{
Logarithmic temperature dependence of the sound velocity in amorphous metallic Ni-P
}

\author{
G. Bellessa, P. Doussineau, A. Levelut
}

\section{To cite this version:}

G. Bellessa, P. Doussineau, A. Levelut. Logarithmic temperature dependence of the sound velocity in amorphous metallic Ni-P. Journal de Physique Lettres, 1977, 38 (2), pp.65-66. 10.1051/jphyslet:0197700380206500 . jpa-00231326

\section{HAL Id: jpa-00231326 https://hal.science/jpa-00231326}

Submitted on 1 Jan 1977

HAL is a multi-disciplinary open access archive for the deposit and dissemination of scientific research documents, whether they are published or not. The documents may come from teaching and research institutions in France or abroad, or from public or private research centers.
L'archive ouverte pluridisciplinaire HAL, est destinée au dépôt et à la diffusion de documents scientifiques de niveau recherche, publiés ou non, émanant des établissements d'enseignement et de recherche français ou étrangers, des laboratoires publics ou privés. 


\title{
LOGARITHMIC TEMPERATURE DEPENDENCE OF THE SOUND VELOCITY IN AMORPHOUS METALLIC Ni-P
}

\author{
G. BELLESSA \\ Laboratoire de Physique des Solides (*), Université Paris-Sud, 91405 Orsay, France \\ and \\ P. DOUSSINEAU and A. LEVELUT \\ Laboratoire d'Ultrasons $\left({ }^{*}\right)$, Université Pierre-et-Marie-Curie, \\ Tour 13, 4, place Jussieu, 75230 Paris Cedex 05, France
}

(Reçu le 15 novembre 1976, accepté le 7 décembre 1976)

\begin{abstract}
Résumé. - Des mesures de vitesse du son dans Ni-P sont présentées. La vitesse des ondes longitudinales et transversales est mesurée à $70 \mathrm{MHz}$ et $150 \mathrm{MHz}$, à partir de $0,37 \mathrm{~K}$. A basse température (au-dessous de $2 \mathrm{~K}$ ) la vitesse suit une loi de température logarithmique comme dans les amorphes isolants. A plus hautes températures, la vitesse décroît linéairement quand la température croît jusqu'à $30 \mathrm{~K}$.
\end{abstract}

\begin{abstract}
Sound velocity measurements in Ni-P are reported. The velocity of longitudinal and transverse waves has been measured at $70 \mathrm{MHz}$ and $150 \mathrm{MHz}$ down to $0.37 \mathrm{~K}$. At low temperatures (below $2 \mathrm{~K}$ ) the velocity follows a logarithmic temperature law as in amorphous insulators. At higher temperatures the velocity decreases linearly as the temperature is increased up to $30 \mathrm{~K}$.
\end{abstract}

A number of attempts have recently been made to observe in amorphous metals the peculiar acoustic properties of amorphous insulators. In a recent paper, Bellessa et al. [1] did not observe any decrease of the sound velocity at low temperature, or any saturation effect in the acoustic attenuation. We report in this letter measurements of the sound velocity in a metallic amorphous material which show a behaviour very similar to that observed in amorphous insulators [2]. This behaviour is well described by the model proposed by Anderson et al. [3] and Phillips [4] which assumes the existence of two-levels systems. It was not observed in [1], owing to too low a sensitivity in the velocity measurements. In the present experiments the sensitivity is one order of magnitude better and this improvement is necessary to reveal a phenomenon which is one order of magnitude smaller than in amorphous insulators.

The Ni-P samples are the same as those used in [1]. The concentration is near the eutectic composition (19 atoms \% of Phosphorous). The longitudinal and transverse wave velocities have been measured as a

$\left(^{*}\right)$ Associated with the Centre National de la Recherche Scientifique. function of temperature down to $0.37 \mathrm{~K}$. The velocity variation was measured with a precision better than $\pm 2 \times 10^{-6}$ (this precision is one order of magnitude better than in [1]). The velocity measurements were performed at $70 \mathrm{MHz}$ and at $150 \mathrm{MHz}$. The longitudinal waves were generated with a X-cut quartz. The transverse waves were generated with a Y-cut quartz. The results for longitudinal and transverse sound waves at low temperature are reported in figure 1. The relative variation is $\left(V(T)-V\left(T_{0}\right)\right) / V\left(T_{0}\right)$ where $T_{0}$ is an arbitrary reference temperature which is $0.37 \mathrm{~K}$ in the present case. In figure 1, each curve has been arbitrarily translated along the $\mathrm{Y}$-axis with respect to the others. Figure 1 shows that the sound velocity variation is similar to that in amorphous insulators [2]: The sound velocity increases with temperature at the lowest temperatures, then decreases at higher temperatures. At the lowest temperatures the experimental points are well fitted with a logarithmic temperature law (straight lines in Fig. 1). The temperature dependence is larger for the transverse waves than for the longitudinal waves. This property is not observed in amorphous insulators where the slopes are nearly equal in the two cases [5]. At high temperature the sound velocity decreases linearly as 


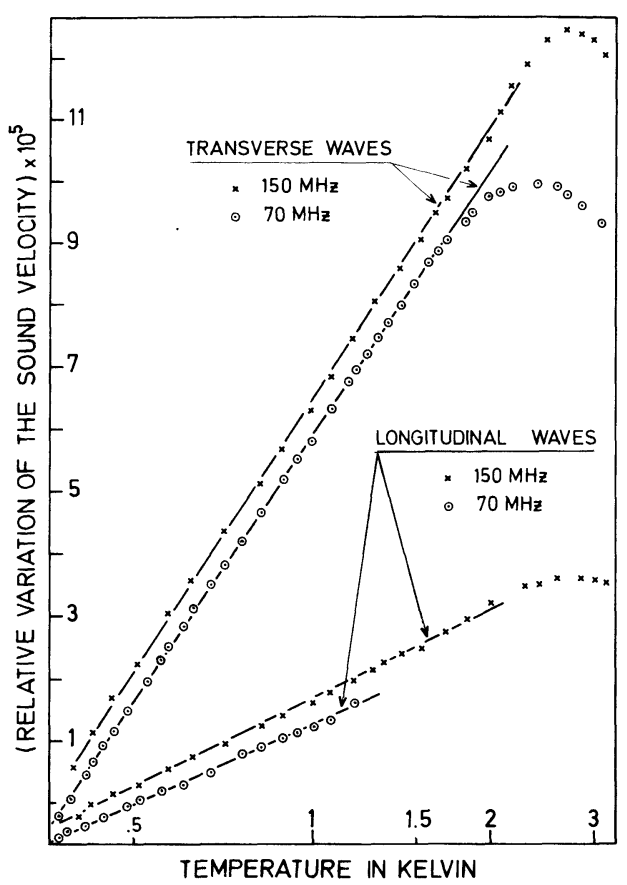

FIG. 1. - Relative variation of the sound velocity as a function of temperature in amorphous Ni-P. The velocity variation is relative to the value for an arbitrary reference temperature which is $0.37 \mathrm{~K}$ in the present case. The $Y$ axis origin for each of the curves is arbitrary. The measurement accuracy is better than $\pm 2 \times 10^{-6}$. The longitudinal wave velocity is $5.2 \times 10^{5} \mathrm{~cm} / \mathrm{s}$. The transverse wave velocity is $2.3 \times 10^{5} \mathrm{~cm} / \mathrm{s}$.

the temperature is increased (Fig. 2). This property has already been observed for the Rayleigh wave velocity [1].

The peculiar temperature dependence of the velocity is caused by the interaction of the sound wave with the two-level systems [2], [6]. At low temperature $(T<2 \mathrm{~K})$, there is a resonant ultrasonic attenuation which leads to an increase of the velocity as the temperature is increased. At higher temperatures a relaxation process leads to a drecrease of the velocity with increasing temperature. We limit ourselves to the behaviour at low temperatures which takes into account the resonant interaction only. Then, the variation of the sound velocity is [2]

$$
\frac{V(T)-V\left(T_{0}\right)}{V\left(T_{0}\right)}=C \ln \left(\frac{T}{T_{0}}\right)
$$

$C$ is the coupling constant $n_{0} G^{2} / 4 \rho V^{2}$ where $n_{0}$ is the two-level system density of states and $V$ is the sound velocity [6]. Eq. (1) is valid for low frequency

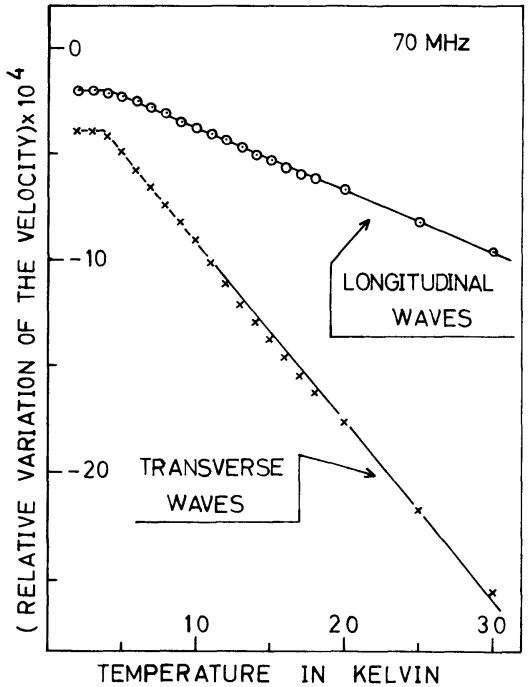

FIG. 2. - Relative variation of the sound velocity as a function of temperature in amorphous Ni-P. The velocity variation is relative to the value for an arbitrary reference temperature which is $3 \mathrm{~K}$ in the present case. The $Y$ axis origin for each of the curves is arbitrary.

sound waves $\left(\hbar \omega \ll k_{\mathrm{B}} T\right)$. The logarithmic temperature dependence agrees with our experimental results (Fig. 1). Fitting these results with eq. (1) and using $\rho=8 \mathrm{~g} / \mathrm{cm}^{3}, V_{1}=5.2 \times 10^{5} \mathrm{~cm} / \mathrm{s}$ and $V_{\mathrm{t}}=2.3 \times 10^{5} \mathrm{~cm} / \mathrm{s}$, we can derive the coupling parameter $n_{0} G^{2}$ for longitudinal and transverse waves respectively. It is not possible to determine $G$ because $n_{0}$ is unknown. We obtain [7]

$$
n_{0} G_{1}^{2} / 4=3.9 \times 10^{7} \mathrm{erg} / \mathrm{cm}^{3}
$$

and

$$
n_{0} G_{\mathrm{t}}^{2} / 4=2.6 \times 10^{7} \mathrm{erg} / \mathrm{cm}^{3} .
$$

These values, as compared with those obtained in amorphous insulators [2], [5], are one order of magnitude smaller.

Our experimental results show that the acoustical properties at low temperatures are qualitatively the same in amorphous metals as in amorphous insulators. (However the coupling constant is one order of magnitude smaller for metals.) This observation is not obvious because the structures are very different in the two cases. In amorphous insulators like $\mathrm{SiO}_{2}$ the structure is not packed and it is possible to imagine some motions of the oxygen atoms between bonding silicon atoms [8]. In the amorphous metals like Ni-P the structure is close-packed [9] and the same mechanisms are more difficult to imagine.

\section{References}

[1] Bellessa, G., Cagnon, M., Sadoc, J. F., Doussineau, P. et LeVelut, A., J. Physique Lett. 37 (1976) L-291.

[2] Piché, L., Maynard, R., Hunklinger, S. and Jäckle, J., Phys. Rev. Lett. 32 (1974) 1426.

[3] Anderson, P. W., Halperin, B. and Varma, C., Phil. Mag. 25 (1972) 1.

[4] Phillips, W. A., J. Low Temp. Phys. 7 (1972) 351.

[5] Hunklinger, S., Schickfus, M. V., Arnold, W., Piché, L. and Dransfeld, K., Low Temperature Physics, L. T. 14
3 (1975) 5, edited by M. Krusius and M. Vuorio (NorthHolland Publishing Company).

[6] Joffrin, J. and Levelut, A., J. Physique 36 (1975) 811.

[7] We use $n_{0} G / 4$ rather than $n_{0} G$ to make our results directly comparable with those in insulators.

[8] Anderson, D. L. and Bömmel, H. E., J. Amer. Ceram. Soc. 38 (1955) 125.

[9] Dixmier, J., Bletry, J. and SAdoc, J. F., J. Physique Colloq. 36 (1975) C2-73. 